\title{
Molecular Characterization of the Asian Tiger Mosquito Aedes albopictus (Skuse) (Diptera: Culicidae) in Northern Italy
}

\author{
Elena Shaikevich $^{1}$ and Asghar Talbalaghi ${ }^{2}$ \\ ${ }^{1}$ Group of Insect Genetics, Department of Comparative Genetics of Animals, N.I. Vavilov Institute of General Genetics, \\ Russian Academy of Sciences, Gubkin Street 3, Moscow 119991, Russia \\ ${ }^{2}$ Mosquito Control District of Alessandria, Spalto Marengo 33, 15121 Alessandria, Italy
}

Correspondence should be addressed to Elena Shaikevich; elenashaikevich@mail.ru

Received 14 February 2013; Accepted 7 March 2013

Academic Editors: P. A. Calatayud and A. Paz Silva

Copyright (c) 2013 E. Shaikevich and A. Talbalaghi. This is an open access article distributed under the Creative Commons Attribution License, which permits unrestricted use, distribution, and reproduction in any medium, provided the original work is properly cited.

Polymorphism of the gene COI encoding cytochrome C oxidase subunit I and of the rRNA second internal transcribed spacer (ITS2) was measured in Aedes albopictus collected in three locations in Piedmont region and one location in Liguria region in Italy. According to our data, besides the middle part of the COI gene usually used for analysis, there are also SNPs in the $5^{\prime}$ half of the gene, which can provide additional information about the polymorphism of A. albopictus populations. Based on COI gene, three various mitochondrial haplotypes were identified in A. albopictus from four north Italian sampling sites. Different sources of introductions can be considered. The variability between COI sequences of the north Italian A. albopictus is 0.001 while the variability between them based on the pairwise analysis of ITS2 sequences is 10 time more- 0.011 . For the first time, a $4 \%$ divergence between the populations of A. albopictus of tropical and subtropical origins was found on the basis of analyzing the ITS2. A relatively high level of variability of ITS2 between tropical and subtropical populations can be used to develop new markers for phylogenetic studies. No individuals with mitochondrial and nuclear haplotypes specific to tropical populations were found in the four north Italian sampling sites.

\section{Introduction}

Aedes albopictus was first detected in Italy in Genova (Liguria) in 1990 [1]. In 2007, it has been incriminated as the main vector of the first European outbreak of chikungunya virus (CHIKV) in northern Italy [2]. A. albopictus from Northern Italy was also demonstrated to efficiently transmit in laboratory CHIKV and to a lesser extent, dengue virus (DENV) [3]. Its expansion all over the world may contribute to obtain a mosaic of genetically distinct populations expressing different abilities to transmit arboviruses [4-7]. Studies using cytochrome $\mathrm{C}$ oxidase subunit I (COI) and NADH dehydrogenase subunit 5 (ND5) genes showed a low level of polymorphism of the mitochondrial DNA (mtDNA), but revealed differences between tropical and subtropical populations [8-12]. Low levels of mtDNA polymorphism can be associated with the founder effect [8], and also with the presence of maternally inherited symbiotic bacterium
Wolbachia in A. albopictus [13]. It is considered that the Wolbachia-infected individuals are favoured owing to the phenomenon of cytoplasmic incompatibility. Unlike the mtDNA, the nuclear DNA is not exposed to the selective sweep of the Wolbachia-infected mitochondrial haplotype. Therefore, genetic variations in nuclear DNA must be higher. Moreover, it was previously shown that the intergenic spacer region of rRNA varied in size from 2 to $10 \mathrm{~kb}$ in A. albopictus populations [14]. The relatively high level of polymorphism was also observed using allozyme markers for north American, Brazilian [15] and Italian populations [16].

As DNA analysis was conducted only for two A. albopictus mosquitoes from Italy [10], we undertook a genetic study of these mosquitoes in northern Italy. We studied genetic diversity within $A$. albopictus from four sampling sites based on analyses of the mitochondrial and nuclear sequences. Since in Croatia, only one common mitochondrial haplotype for the ND5 gene and four different mitochondrial haplotypes 
for the COI gene were detected [12] and in Cameroon four other mitochondrial haplotypes of the COI gene were found in the absence of polymorphism of the ND5 gene [11], we selected COI as the most informative gene for analysis of $A$. albopictus from different sampling sites. COI is also used for Barcoding and published sequence data of different geographical origin are available for analysis. To study nuclear gene diversity within and among of $A$. albopictus from different sampling sites, we investigated the second internal transcribed spacer (ITS2) of rRNA that is traditionally used to identify interspecific differences. ITS2 was successfully used to differentiate the Aedes species [10].

Using COI and ITS2 as genetic markers, we determined the geographic origin of $A$. albopictus invading northern Italy. These data will help to predict further expansion of $A$. albopictus on the European continent and to develop measures to counteract.

\section{Materials and Methods}

A. albopictus mosquitoes were collected in four locations in northern Italy during the summer of 2009 and 2011: Piovera $44^{\circ} 57^{\prime} 35.14^{\prime \prime} \mathrm{N}, 8^{\circ} 44^{\prime} 14.23^{\prime \prime} \mathrm{E}$ (2 individuals), Tortona $44^{\circ} 53^{\prime} 39^{\prime \prime} \mathrm{N}, 8^{\circ} 56^{\prime \prime} \mathrm{E}$ (2 individuals), Alessandria $44^{\circ} 55^{\prime} 21.47^{\prime \prime} \mathrm{N}, 8^{\circ} 38^{\prime} 00.91^{\prime \prime} \mathrm{E}$ (11 individuals) from Piedmont region, and Varazze $44^{\circ} 21^{\prime} 37.79^{\prime \prime} \mathrm{N}, 8^{\circ} 34^{\prime} 33.88^{\prime \prime} \mathrm{E}$ (19 individuals) from Liguria region. Altogether, 34 specimens were investigated.

For identification were used Identification Key by Stojanovich and Scott and the Key proposed by Michele M. Cutwa-Francis and George F. O'Meara. A further, certainty in the eggs identification is based on the multiannual experience yet unpublished, in proposed, by Asghar Talbalaghi, for identification of eggs of A. albopictus which are very similar to the species of Ochlerotatus geniculatus (http://www .zanzare.eu/pdf/Talbalaghi_Italy_2010.pdf).

Part of a project mosquitoes control-Alessnadria active since 1996 in 30 municipalities in the county of Alessandria, the first ovitraps were positioned in 2004 to monitor eventual arrival from untreated areas outside our jurisdiction. The first record of positive dates back to 2007 with 3 positive cases on 20 ovitraps positioned. To highlight the capacity of $A$. albopictus to spread everywhere once colonized in a certain area, we recorded of 250 ovitraps positioned during the campaign of 2012 from April to November in Province of Alessandria, 150 of ovitraps resulted positive at least a week. The black glass of PVC used by ovitraps are installed from May until the end of November and checked every week by changing the wooden strips and observed in laboratory of Mosquito Control by Talbalaghi by using Microscope 60x.

Besides, further observations of $A$. albopictus were carried out in occasions of first evaluation of BG traps. The ovitrap installed in Varazze, a few kilometers far from Genoa port in the Liguria Region, are installed to sate most in-depth and comparative genetic studies and for the comparison of vector competence of the population on the other side of the Apennines that separates Alessandria from Genoa $80 \mathrm{~km}$ far.

DNA was isolated from ethanol-preserved adult mosquitoes. PCR amplification of the COI gene was performed using the primers TY-J-1460 [17] and COIR2 [18]. The mosquitoes were tested for Wolbachia infection using PCR with primers wsp81F and wsp691R complementary to the gene wsp [19]. The ITS2 region was amplified using primers complementary to the 5,8S and 28S rRNA [20]. The DNA extraction and PCR were performed according to previously described methods [18].

Fourteen PCR products of COI gene and twelve PCR products of ITS2 were sequenced from samples of A. albopictus from four native sampling sites. The newly determined nucleotide sequences of the COI gene and ITS2 region were submitted to GenBank under accession numbers JX679373JX679398.

The obtained sequences were analyzed using software Chromas (http://www.technelysium.com.au/), phylogenetic analyses were conducted in MEGA5 [21]. Estimates of Average Evolutionary Divergence over all Sequence Pairs were conducted using the Maximum Composite Likelihood method in MEGA5. The average evolutionary divergence estimated as number of base substitutions per site from averaging over all sequence pairs within and between each group. All results are based on the pairwise analysis of 24 known to date sequences of ITS2. All positions containing gaps and missing data were eliminated from the dataset (Complete deletion option). There were a total of 346 positions in the final dataset.

Phylogenetic tree was inferred using the Neighbor-Joining method. The optimal tree with the sum of branch length of 0.11842934 is shown (Figure 2). The percentage of replicate trees in which the associated taxa clustered together in the bootstrap test (1000 replicates) is shown next to the branches. The tree is drawn to scale, with branch lengths in the same units as those of the evolutionary distances used to infer the phylogenetic tree. The evolutionary distances were computed using the Maximum Composite Likelihood method and are givenin the units of the number of base substitutions per site. All positions containing gaps and missing data were eliminated from the dataset (complete deletion option).

\section{Results and Discussion}

Polymorphism of the COI gene mtDNA was examined in a $686 \mathrm{bp}$ fragment of sequences of the 9 specimens of $A$. albopictus from three locations in Piedmont region and 5 specimens from one location in Liguria region, Italy. In total, we found only 2 variable nucleotide sites $(0.3 \%)$ in the 14 DNA sequences studied; both were considered informative under the conditions of parsimony (Figure 1). Among the sequences analyzed, all detected substitutions were found to be transitions $A \leftrightarrow G$ located at the first codon position and affecting the amino acid sequence. The number of base substitutions per site from averaging over all sequence pairs is 0.001 based on the pairwise analysis of 14 sequences. Intrapopulation polymorphism was detected in three of the four studied sampling sites. All of them were sampling sites from Piedmont. Individuals from Varazze, Liguria, were monomorphic in nucleotide composition of COI.

In order to determine the geographic origin and phylogenetic relationships of $A$. albopictus invading northern 


\begin{tabular}{|c|c|c|c|}
\hline [ & 1223333 & $4556]$ & [ \\
\hline [ & 4782241469 & 60241 & 122480 \\
\hline[ & 7402081641 & $3866]$ & 657134 \\
\hline \#Pioveral & TGGGAGTG TG & $\mathrm{T} \mathrm{T} \mathrm{GG}$ & S V VDAS \\
\hline \#Piovera2 & $\ldots A \ldots \ldots$ & $\ldots$ & $\ldots I \ldots$ \\
\hline \#Tortona1 & $\ldots \ldots \ldots$ & & $\ldots$ \\
\hline \#Tortona2 & $\ldots \mathrm{A} \ldots \ldots$ & & $\ldots I \ldots$ \\
\hline \#Alessandria1 & $A A \ldots \ldots$ & $\ldots$ & I I . . \\
\hline \#Alessandria2 & $\ldots A \ldots \ldots$ & $\ldots$ & $I$. \\
\hline \#Alessandria3 & $\ldots \ldots \ldots$ & $\ldots$ & $\ldots$ \\
\hline \#Alessandria4 & $\ldots \mathrm{A} \ldots \ldots$ & $\ldots$ & $\ldots I \ldots$ \\
\hline \#Alessandria5 & $A A \ldots \ldots$ & $\ldots$ & I I . . \\
\hline \#Varazze1 & $\ldots \ldots \ldots$ & $\cdots$ & $\cdots$ \\
\hline \#Varazze2 & $\ldots \ldots \ldots$ & $\ldots$ & $\ldots \ldots$ \\
\hline \#Varazze3 & $\ldots \ldots \ldots$ & $\ldots$ & $\ldots$ \\
\hline \#Varazze4 & $\ldots \ldots \ldots$ & $\ldots$ & . \\
\hline \#Varazze5 & $\ldots \ldots \ldots$ & $\ldots$ & $\ldots$. \\
\hline \#AY748238_Italy & NNNNN ... & $\ldots$ & N N NN. \\
\hline \#JF810659_Greece & N.A....... & $\ldots$ & N.I. . \\
\hline \#AY748238_Greece & NNNNN ... & $\ldots$ & N N NN. \\
\hline \#AY748239_Greece & NNNNN.C. & $\ldots$ & NN NN.P \\
\hline \#JQ388786_Germany & $\ldots \ldots \ldots$ & $\ldots$ & $\ldots$. \\
\hline \#JQ004524_haplotypeH1 & $\ldots \ldots \ldots$ & $\ldots$ & $\ldots$. \\
\hline \#JQ004525_haplotypeH2 & $\ldots A \ldots \ldots$ & $\ldots$ & $\ldots I \ldots$ \\
\hline \#HE820720_Russia & NNNNNN . R & $\ldots \mathrm{A}$ & N N NNN. \\
\hline \#AJ971008_France & NNNN .... & $\ldots$ & N N NN . \\
\hline \#AJ971012_Reunion & NNNN . . A . & $\ldots$ & N N NN. \\
\hline \#JN406675_Madagascar & NNNN ..... & $\ldots$ & N N NN. \\
\hline \#AJ971005_USA & NNNN . . . & $\ldots$ & N N NN. \\
\hline \#GQ143719_Australia & C. ACCA... & . C. & P. IH T. \\
\hline \# AB690835_Japan & $\ldots A \ldots \ldots$ & $\ldots$ & $\ldots I \ldots$ \\
\hline \#HQ398901_Vietnam & $\ldots \mathrm{A} \ldots \ldots \mathrm{A}$ & $\ldots$ & $\ldots I \ldots$ \\
\hline \#HQ906848_Croatia_CRO1 & NNNNN . . . & $\ldots$ & NNNN. \\
\hline \#HQ906849_Croatia_CRO2 & NNNNN . . C . & $\ldots$ & N N NN. \\
\hline \#HQ906850_Croatia_CRO3 & NNNNN . . . & . A. & NN N . \\
\hline \#HQ906851_Croatia_CRO4 & NNNNN . . C . & $\ldots$ & N N NN . \\
\hline \#AJ971014_Brazil & NNNN . . C . & $\ldots$ & N N NN. \\
\hline \#JQ235749_China & $\ldots A \ldots C$. & $\ldots$ & $\ldots I \ldots$ \\
\hline \#JF309317_Cameroon_H1 & NNNNN . . C . & $\ldots \mathrm{A}$ & N N N N \\
\hline \#JF309318_Cameroon_H2 & NNNNN . . C . & $\ldots$ & NNNN. \\
\hline \#JF309319_Cameroon_H3 & NNNNN . . C . & C ... & NNNN. \\
\hline \#JF309320_Cameroon_H4 & NNNNN . C C. & . A. & N N N N \\
\hline
\end{tabular}

FIgURE 1: Alignment showing variable nucleotide and variable amino acid sites of the gene COI in A. albopictus. The numbers on the top of the alignment indicate the position number of variable sites in the sequence. $\mathrm{N}$ represents unknown sites that fall out of the analysis in the study of only the middle part of the gene.

Italy, COI sequences recorded in northern Italy and sequence data previously published in GenBank were aligned (Figure 1). In all investigated sequences $\mathrm{T}$ ( $\mathrm{A}$ in the complementary strand) is located at position 364, which distinguishes temperate/subtropical populations from all tropical populations characterized by $C(G)$ in this position. The most frequent studied mitochondrial haplotype (57\%) was detected in all populations. This variant is identical to the mitochondrial haplotype found in southern Germany. A second mitochondrial haplotype was detected in all three sampling sites in Piedmont region and was absent in Liguria region. This mitochondrial haplotype differs from the first by one nucleotide substitution at position 80 and is identical to those found in Japan and Greece. The third mitochondrial haplotype 


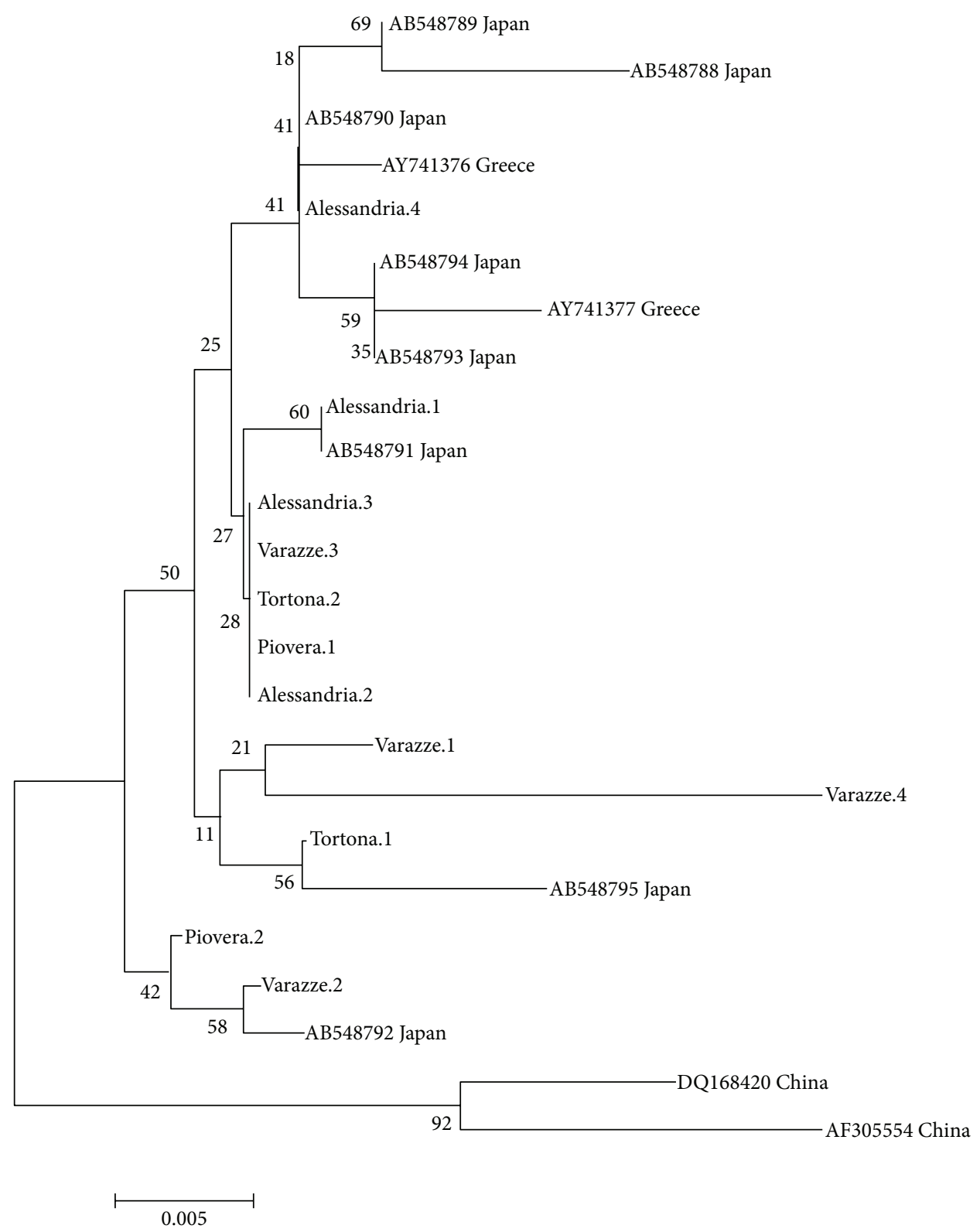

FIGURE 2: Evolutionary relationships of A. albopictus based on the ITS2 analysis. The evolutionary history was inferred using the NeighborJoining method. There were a total of 346 positions in the final dataset. Phylogenetic analyses were conducted in MEGA5. Previously published sequence data are shown together with their GenBank accession numbers.

observed by us for the first time differs from the second by one transition $A \leftrightarrow G$ at position 74 and was found only in the sampling site of Alessandria in Italy.

As shown in Figure 1, many already known mitochondrial haplotypes vary in this $5^{\prime}$ part of the COI gene and it could provide additional information about the polymorphism of European populations and save as a new marker sequence. This part of the sequences (approximately $240 \mathrm{bp}$ ) was lost when only the middle part of the gene is sequenced.

To study nuclear gene diversity within and among of A. albopictus from various sampling sites, we investigated ITS2 region used to differentiate the Aedes species. Typically, about 515-bp amplification products were obtained after amplification with primers $5.8 \mathrm{~S}$ and $28 \mathrm{~S}$ for all 34 mosquitoes studied. 4 samples from Alessandria, 4 samples from Varazze, 2 samples from Piovera, and 2 samples from Tortona were sequenced. Conservative DNA sequences of the $5.8 \mathrm{~S}$ and $28 \mathrm{~S}$ rRNA genes were identical in all studied mosquitoes and were removed from the analysis. The obtained ITS2 sequences were $391-397 \mathrm{bp}$ in length. 16 variable sites $(4.8 \%)$ and 5 indels were found. In $3^{\prime}$ region of the ITS2, we detected TAGTCGC duplication in one sample from Alessandria and one sample from Varazze (data not shown). We have compared the genetic diversity of ITS2 within and between our studied sampling sites and with that of A. albopictus from northwestern Greece, Japan, and China. Only these 
TABLE 1: Estimates of average evolutionary divergence in the ITS2 over sequence pairs within and between A. albopictus populations.

\begin{tabular}{lcccc}
\hline & Italy & Greece & Japan & China \\
\hline $\begin{array}{l}\text { Within } \\
\text { between }\end{array}$ & 0.009 & 0.012 & 0.013 & 0.020 \\
$\begin{array}{l}\text { Italy } \\
\text { Greece }\end{array}$ & 0.013 & & & \\
Japan & 0.011 & 0.012 & & \\
China & 0.037 & 0.043 & 0.041 & \\
\hline
\end{tabular}

sequences of ITS2 of A. albopictus are known to date and are available in GenBank (Table 1). The average evolutionary divergence was estimated as a number of base substitutions per site from averaging over all sequence pairs within and between each group. Intrapopulation diversity is similar in all compared populations. The differences between the populations of Italy, Greece, and Japan are comparable to variability within these populations. The population of China is different from the others.

The dendrogram shows clearly that based on the ITS2 analysis, A. albopictus specimens are clustered into two groups. The first consists of Italian, Greek, and Japanese mosquitoes, all of subtropical origin. The second cluster includes mosquitoes from China, which have a tropical origin. Within the first cluster, there is no population specific haplotypes and individuals from different populations are not grouped together (Figure 2).

The overall average variability between $\mathrm{COI}$ sequences of north Italian A. albopictus is 0.001 while the overall average variability between them based on the pairwise analysis of ITS2 sequences is 10 time more-0.011. As expected, the polymorphism in nuclear DNA is higher than in mtDNA. Nucleotide differences in ITS2 did not allow us to detect differences between $A$. albopictus from different sampling sites in northern Italy. At the same time, based on the analysis of ITS2, there was a $4 \%$ divergence between Chinese mosquitoes of tropical origin and all other mosquitoes of subtropical origin investigated until now on the basis of their $\mathrm{mtDNA}$. However, the sequences from more individuals of geographically remote habitats should be studied. A relatively high level of genetic variability of ITS2 between tropical and subtropical populations can be used to develop markers that will provide additional information about spreading and possible hybridization of $A$. albopictus with different origins.

All 34 studied mosquitoes were also tested for Wolbachia infection using PCR with primers for Wolbachia surface protein (wsp) gene. PCR products of the expected size about $620 \mathrm{bp}$ were obtained from individuals from two sampling sites-Piovera and Tortona. The PCR showed no positive results for individuals from two other sampling sites-Alessandria and Varazze. The DNA of all uninfected individuals was positive for PCR amplification using primers for COI and ITS2, indicating satisfactory of DNA template quality. Polymorphism of the COI gene in different sampling sites together with various Wolbachia infection status may indicate that the studied $A$. albopictus did not originate from a single ancestor population. Different sources of introductions can be considered.

It is important that to date no individuals with mitochondrial and nuclear haplotypes specific to tropical populations were detected in the study area. Individuals with tropical mitochondrial haplotypes were found in 2009 in Croatia [12]. The identity of the corresponding nuclear DNA remained unknown. It is not known whether there are barriers to genetic exchanges between A. albopictus of the subtropical and tropical origins in Europe, although the absence of genetic exchange between the Brazil (tropical origin) and the United States (subtropical) populations was proved [8]. Biological features such as the ability to entering in diapause and feeding preferences may affect the vector capacity. Study of mtDNA allows to determine the origin through the maternal line, whereas investigation of nuclear DNA can provide information on hybridization. Determination of the genetic structure of vector populations will allow developing strategies only targeting competent vectors.

\section{Conclusions}

The present study revealed three mitochondrial haplotypes based on COI gene and various Wolbachia infection status in A. albopictus from four sampling sites in northern Italy. Different sources of introductions can be considered.

For the first time, a $4 \%$ divergence between the populations of A. albopictus of tropical and subtropical origins was found on the basis of analyzing the ITS2.

No individuals with mitochondrial and nuclear haplotypes specific to tropical populations were found in the studied northern Italian populations.

\section{Acknowledgments}

The authors are very grateful to Anna-Bella Failloux for helpful editorial corrections. This work was supported by the Program of Basic Research of the Russian Academy of Sciences "Wildlife: Current Status and Problems of Development" and Project mosquitoes control-Alessnadria. In order to evaluate control activity please see the innovative monitoring system updated through the web page using google Map of activity of Talbalaghi: http://www.zanzare.eu/alessandria/? $\mathrm{m}=55$ (clic on tiger mosquito Tiger Mosquito Surveillance Network-Google Maps).

\section{References}

[1] A. Sabatini, V. Raineri, G. Trovato, and M. Coluzzi, "Aedes albopictus in Italy and possible diffusion of the species into the Mediterranean area," Parassitologia, vol. 32, no. 3, pp. 301-304, 1990.

[2] G. Rezza, L. Nicoletti, R. Angelini et al., "Infection with chikungunya virus in Italy: an outbreak in a temperate region," The Lancet, vol. 370, no. 9602, pp. 1840-1846, 2007.

[3] A. Talbalaghi, S. Moutailler, M. Vazeille, and A. B. Failloux, "Are Aedes albopictus or other mosquito species from northern Italy competent to sustain new arboviral outbreaks?" Medical and Veterinary Entomology, vol. 24, no. 1, pp. 83-87, 2010. 
[4] R. D. Boromisa, K. S. Rai, and P. R. Grimstad, "Variation in the vector competence of geographic strains of Aedes albopictus for dengue 1 virus," Journal of the American Mosquito Control Association, vol. 3, no. 3, pp. 378-386, 1987.

[5] R. Lourenço-de-Oliveira, M. Vazeille, A. M. Bispo-de-Filippis, and A. B. Failloux, "Large genetic differentiation and low variation in vector competence for dengue and yellow fever viruses of Aedes albopictus from Brazil, the United States, and the Cayman Islands," The American Journal of Tropical Medicine and Hygiene, vol. 69, no. 1, pp. 105-114, 2003.

[6] S. Lozano-Fuentes, I. Fernandez-Salas, M. de Lourdes Munoz et al., "The neovolcanic axis is a barrier to gene flow among Aedes aegypti populations in Mexico that differ in vector competence for dengue 2 virus," PLoS Neglected Tropical Diseases, vol. 3, no. 6, article e468, 2009.

[7] G. Rezza, "Aedes albopictus and the reemergence of Dengue," BMC Public Health, vol. 12, article 72, 2012.

[8] J. Birungi and L. E. Munstermann, "Genetic structure of Aedes albopictus (diptera: Culicidae) populations based on mitochondrial ND5 sequences: evidence for an independent invasion into Brazil and United States," Annals of the Entomological Society of America, vol. 95, no. 1, pp. 125-132, 2002.

[9] L. Mousson, C. Dauga, T. Garrigues, F. Schaffner, M. Vazeille, and A. B. Failloux, "Phylogeography of Aedes (Stegomyia) aegypti (L.) and Aedes (Stegomyia) albopictus (Skuse) (Diptera: Culicidae) based on mitochondrial DNA variations," Genetical Research, vol. 86, no. 1, pp. 1-11, 2005.

[10] E. Patsoula, A. Samanidou-Voyadjoglou, G. Spanakos, J. Kremastinou, G. Nasioulas, and N. C. Vakalis, "Molecular and morphological characterization of Aedes albopictus in northwestern Greece and differentiation from Aedes cretinus and Aedes aegypti," Journal of Medical Entomology, vol. 43, no. 1, pp. 40-54, 2006.

[11] B. Kamgang, C. Brengues, D. Fontenille, F. Njiokou, F. Simard, and C. Paupy, "Genetic structure of the tiger mosquito, Aedes albopictus, in Cameroon (central Africa)," PLoS ONE, vol. 6, no. 5, Article ID e20257, 2011.

[12] T. Zitko, A. Kovacic, Y. Desdevises, and J. Puizina, "Genetic variation in east-adriatic populations of the Asian tiger mosquito, Aedes albopictus (Diptera: Culicidae), inferred from NADH5 and COI sequence variability," European Journal of Entomology, vol. 108, no. 4, pp. 501-508, 2011.

[13] P. Armbruster, W. E. Damsky, J. R. Giordano, J. Birungi, L. E. Munstermann, and J. E. Conn, "Infection of New- and OldWorld Aedes albopictus (Diptera: Culicidae) by the Intracellular Parasite Wolbachia: implications for host mitochondrial DNA evolution," Journal of Medical Entomology, vol. 40, no. 3, pp. 356-360, 2003.

[14] C. C. N. Wu and A. M. Fallon, "Analysis of a ribosomal DNA intergenic spacer region from the yellow fever mosquito, Aedes aegypti," Insect Molecular Biology, vol. 7, no. 1, pp. 19-29, 1998.

[15] S. Kambhampati, W. C. Black IV, and K. S. Rai, "Geographic origin of the US and Brazilian Aedes albopictus inferred from allozyme analysis," Heredity, vol. 67, no. 1, pp. 85-94, 1991.

[16] S. Urbanelli, R. Bellini, M. Carrieri, P. Sallicandro, and G. Celli, "Population structure of Aedes albopictus (Skuse): the mosquito which is colonizing Mediterranean countries," Heredity, vol. 84, no. 3, pp. 331-337, 2000.

[17] C. S. Simon, F. Frati, A. Beckenbach, B. Crespi, H. Liu, and P. Flook, "Evolution, weighting, and phylogenetic utility of mitochondrial gene sequences and a compilation of conserved polymerase chain reaction primers," Annals of the Entomological Society of America, vol. 87, no. 6, pp. 651-701, 1994.

[18] E. V. Shaikevich and I. A. Zakharov, "Polymorphism of mitochondrial COI and nuclear ribosomal ITS2 in Culex pipiens complex and in Culex torrentium (Diptera, Culicidae)," Comparative Cytogenetics, vol. 4, no. 2, pp. 161-174, 2010.

[19] H. R. Braig, W. Zhou, S. L. Dobson, and S. L. O’Neill, “Cloning and characterization of a gene encoding the major surface protein of the bacterial endosymbiont Wolbachia pipientis," Journal of Bacteriology, vol. 180, no. 9, pp. 2373-2378, 1998.

[20] C. H. Porter and F. H. Collins, "Species-diagnostic differences in a ribosomal DNA internal transcribed spacer from the sibling species Anopheles freeborni and Anopheles hermsi (Diptera: Culicidae)," American Journal of Tropical Medicine and Hygiene, vol. 45, no. 2, pp. 271-279, 1991.

[21] K. Tamura, D. Peterson, N. Peterson, G. Stecher, M. Nei, and S. Kumar, "MEGA5: molecular evolutionary genetics analysis using maximum likelihood, evolutionary distance, and maximum parsimony methods," Molecular Biologyand Evolution, vol. 28, no. 10, pp. 2731-22739, 2011. 

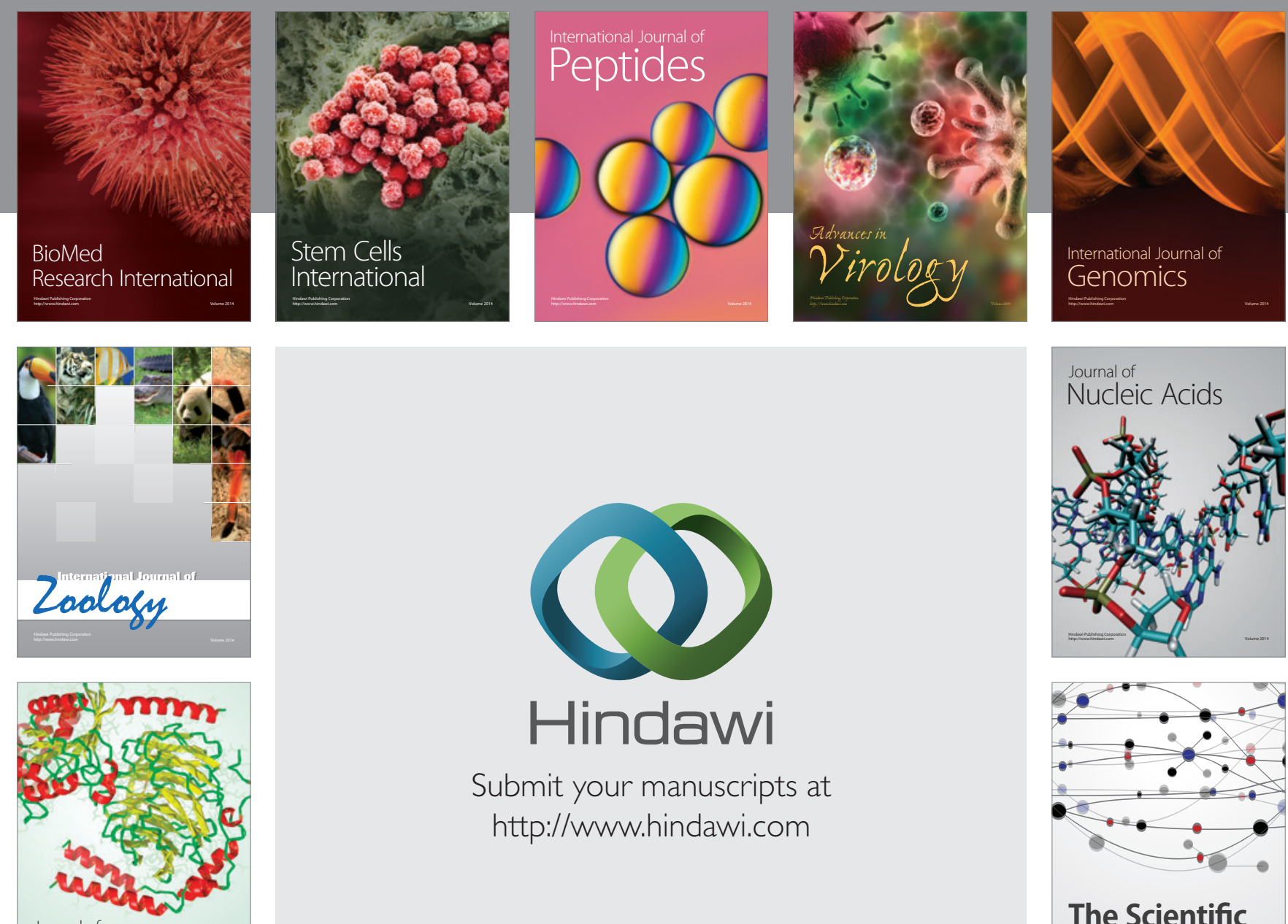

Submit your manuscripts at

http://www.hindawi.com

Journal of
Signal Transduction
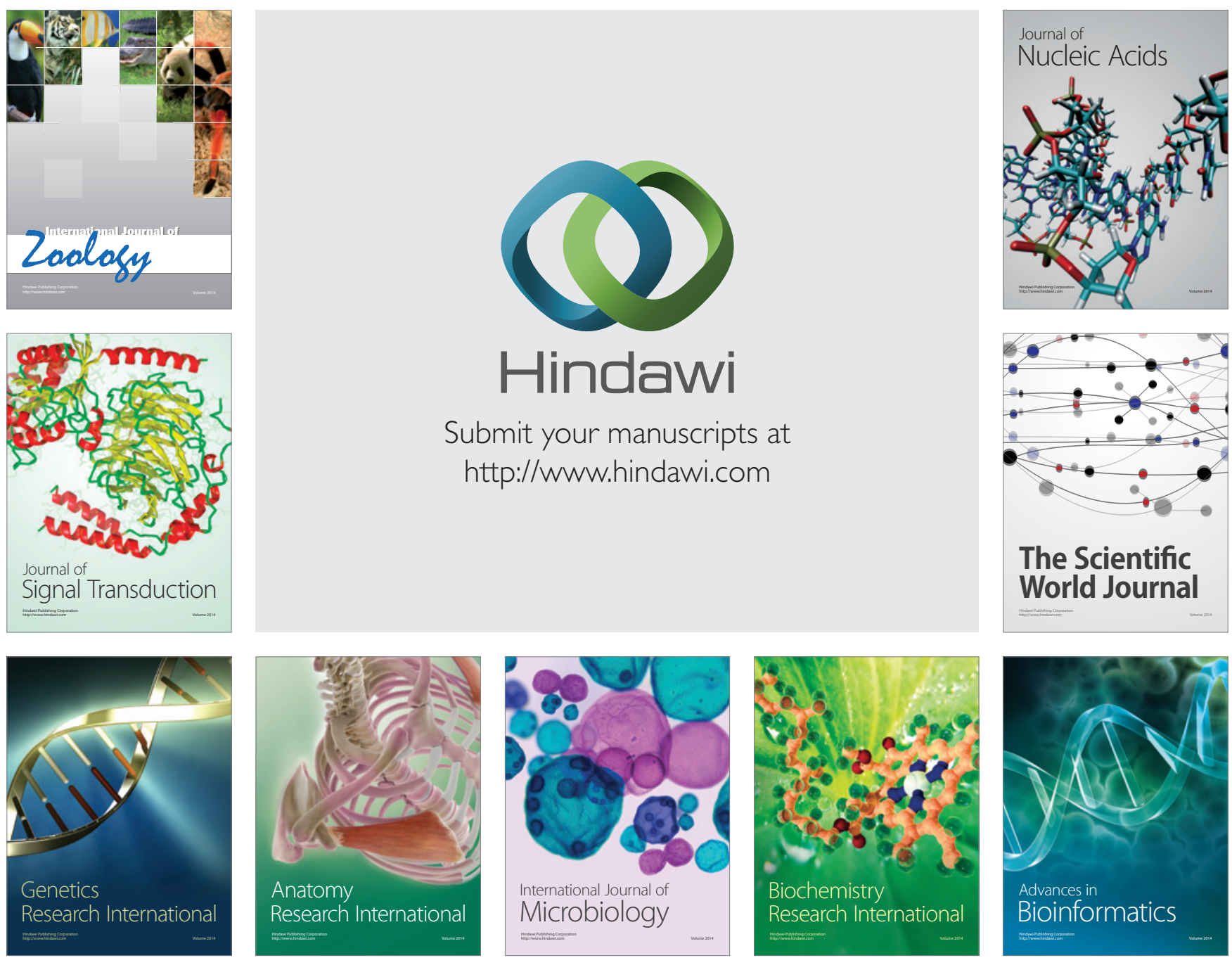

The Scientific World Journal
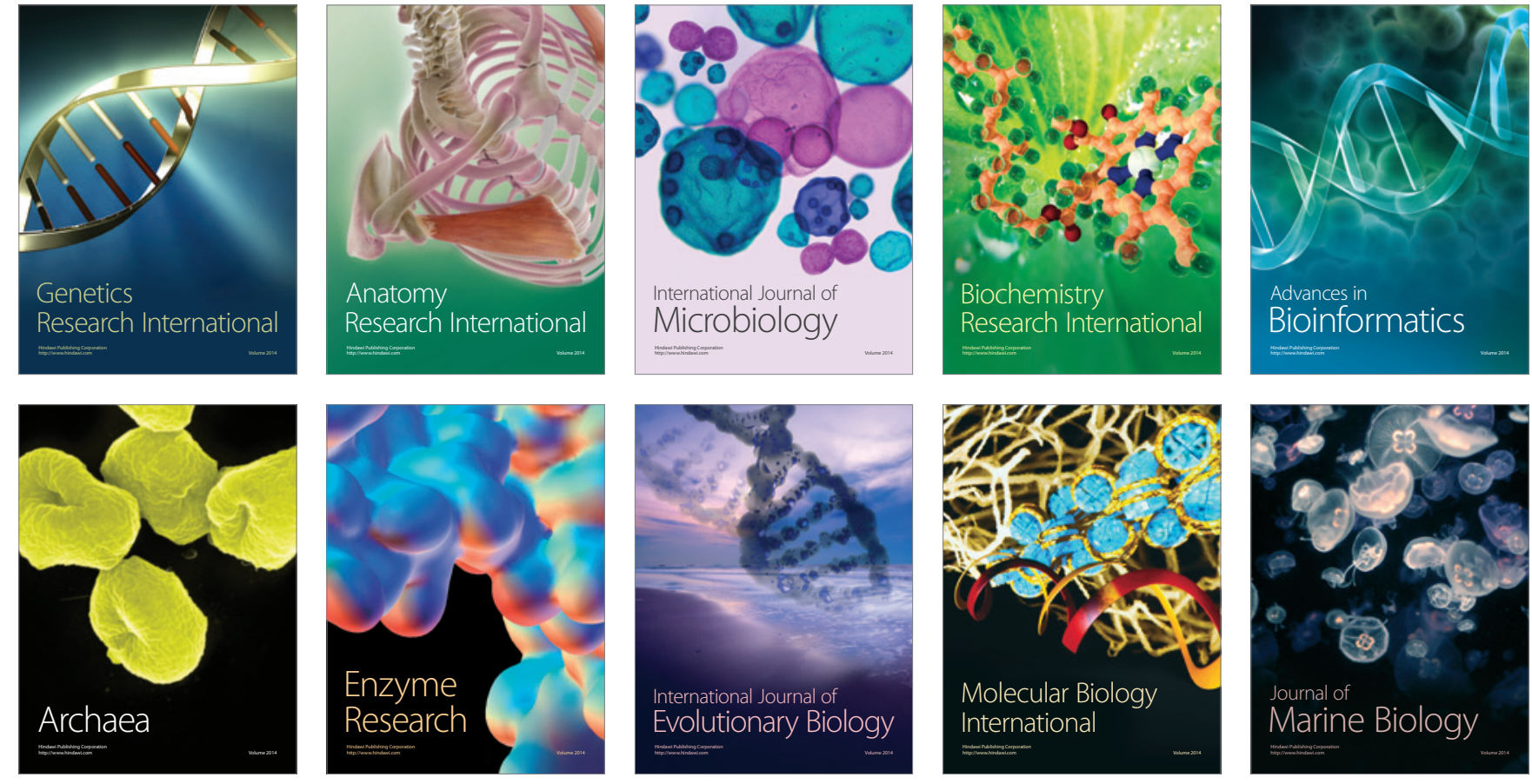